\title{
A proposal new classification in multi-ligament knee injuries based on both femorotibial joint and patellofemoral joint factors
}

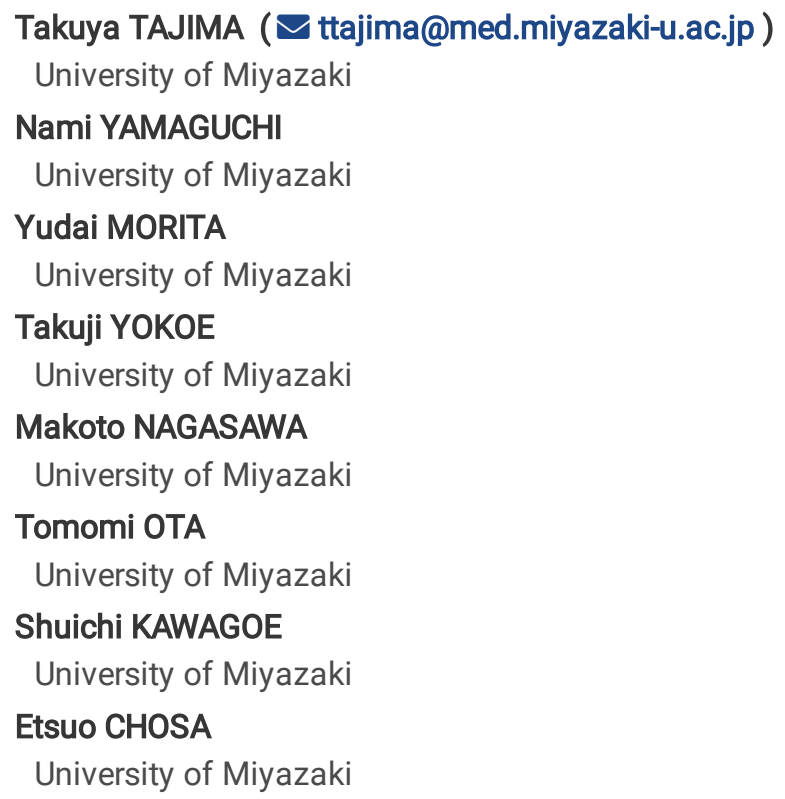

\section{Research Article}

Keywords: Multi-ligament knee injury, femorotibial joint, patellofemoral joint, periarticular fracture, neurovascular injury

Posted Date: February 7th, 2022

DOI: https://doi.org/10.21203/rs.3.rs-1267423/v1

License: (1) This work is licensed under a Creative Commons Attribution 4.0 International License. Read Full License 


\section{Abstract}

Background

Knee extensor structure disruption is sometimes combined with multi-ligament knee injury (MLKI). These cases could not be classified into the previous classification for knee dislocation or MLKI. To propose a new classification of MLKI that addresses both femorotibial and patellofemoral (PF) factors.

Methods

The present study involved patients diagnosed with MLKI at our institute. Cases with two or more injured structures diagnosed clinically and by MRI and X-ray examinations were included. Details of injured structures were defined as follows: 'cruciate ligaments', including the $\mathrm{ACL}$ and PCL; 'collateral ligaments', including the MCL and the posterolateral corner (PLC); and the 'PF joint factor', including the medial patellofemoral ligament (MPFL), quadriceps tendon, and patellar tendon. A total of 65 cases met the inclusion criteria from 2007 to August 2020 and were enrolled in this study.

Based on the number of injured structures, cases were categorized as: Type A, two structures injured; Type B, three structures injured; Type C, four structures injured; and Type D, five structures injured. Depending on the combination of injured structures, they were subdivided into 1 to 5 in Types $A$ and $B$ and into 1 to 3 in Type $C$. Additional injuries were subdivided as follows: MLKI with fracture was defined as $\mathrm{X}$, with neurovascular injury as $\mathrm{Y}$, and both fracture and neurovascular injury as $\mathrm{Z}$. MLKI cases were divided into both Schenck's KD classification and the present classification.

Results

Fourteen of 65 cases $(21.5 \%$ ) could not be categorized using Schenck's KD classification; two cases of PLC+MPFL (Type-A5 in new classification), $A C L+P L C$ with periarticular fracture (Type-A1-X), and single cases of $A C L+M C L+P L C$ (Type-B2),

$\mathrm{ACL}+\mathrm{PCL}+\mathrm{MCL}+\mathrm{PLC}+\mathrm{MPFL}$ (Type-D), ACL+MPFL (Type-A4), ACL+MCL+MPFL (Type-B3), PCL+PLC+ patellar tendon with periarticular fracture (Type-B3-X), and PCL+ patellar tendon (Type-A4), ACL+PLC with neurovascular injury (Type-A1-Y), and three cases of PCL+PLC with complications (Type-A1-X, -Y, -Z). With the new classification for MLKI and complications, all cases were successfully assigned to each category.

Conclusion

In the present classification, every combination of MLKI cases containing both tibiofemoral and patellofemoral factors, with or without complications, was successfully classified into a suitable category.

\section{Introduction}

Multi-ligament knee injuries (MLKIs) occur as a result of high-energy trauma such as traffic accidents, fall accidents, and sports accidents. MLKIs show varied symptoms that depend on the combination of injured structures moreover, with additional periarticular fractures, nerve injury, and vascular injury in some MLKI cases [1]. MLKIs induce severe knee joint instability and leg disability. Therefore, careful assessment or examination is required for the diagnosis and treatment of MLKI [2].

The knee extensor mechanism, which consists of the quadriceps tendon, patella, and patellar tendon, is one of the important factors that determine knee function. Dislocation of the patella or quadriceps or patellar tendon rupture causing severe instability or disability of knee function. Of course, such injuries are also the part of the treatment regimen when considering treatment, be it repair or reconstruction. Sometimes, the knee extensor structure disruption is combined with injuries of other knee ligaments $[3,4]$.

Several classification systems have been reported for the diagnosis of knee dislocation and MLKI cases. Kennedy's classification was focused on dislocation direction of the knee [5]. The French Society of Orthopedic Surgery and Traumatology (SOFCOT) 2008 classification classified into four categories based on the two main concepts of the mechanism of knee injury: gapping and translation [6]. These classifications were focused on the femorotibial joint. Schenck's knee dislocation (KD) classification was also one of the great classifications of knee dislocation and MLKI for surgeons with respect to decision-making [7, 8]. Basically, KD classification was based on the combination of injured ligaments with or without the presence of fracture. However, KD classification also referred only to the cruciate and collateral ligaments. Therefore, it was reported that the KD classification in isolation was not predictive of any surgical 
management strategy [9]. Cases of combined cruciate or collateral ligament injuries with knee extensor structure disruption could not be classified in these previous classifications. For example, the anterior cruciate ligament (ACL) and patellar tendon or medial patellofemoral ligament (MPFL) rupture cases that showed knee joint instability and disability and surgeons must consider treatment for both involved structures, were not included in the previous classifications, even though two structures around the knee joint had failed.

The information about the number and combination of injured structures may affect surgical procedures and strategy with regard to the graft selection, surgical timing, surgical procedure and so on. Therefore, we proposed a new classification for MLKI to cover all combination of collateral ligaments, cruciate ligaments, and knee extensor structure in other words, patellofemoral (PF) joint factor. Based on KD classification, we established and defined several categories in accordance with the number and combination of injured structures, and additional combined injuries such as periarticular fractures, nerve injury, and vascular injury. It was hypothesized that all cases with at least two structures involved, not only a combination of femorotibial joint factors, but also PF joint factors and complications, could be classified using the new classification.

\section{Methods}

\section{Patients}

The present study was conducted in 2019, involving patients who were diagnosed with MLKI at our institute. The experimental design was reviewed and approved (Approval number No. 0-0602) by the Ethics Committee of our institute. The procedures followed were in accordance with the ethical standards of the responsible committee on human experimentation (institutional and national) and with the Helsinki Declaration of 1975, as revised in 2013. Information regarding the conduct of this study was disclosed, and research subjects (cases 1-61) were given the opportunity to refuse inclusion in this study. Written, informed consent was obtained from all patients and guardians of prospective research subjects (cases 62-65) for publication of this report and any accompanying images before entering their entry into this study. The patients who did not want to take part were not enrolled in this study. The study involved both a retrospective and a prospective observational design, with data collected from May 2007 to August 2020.

Basically, three senior orthopedic surgeons performed full physical examinations of each structure around the knee joint. Cases of two or more injured structures diagnosed clinically by the presence of the anterior/posterior drawer sign, Lachman test and pivot shift test, abnormal varus/valgus laxity, dial testing, and patellar subluxation, instability, and dislocation, as well as by magnetic resonance imaging (MRI), computed tomography (CT), and dynamic X-ray testing, were included. Cases with any prior knee surgery were excluded. A total of sixty-five MLKI cases visited our institute and were provided surgical treatment due to knee instability and disability during the investigation period. No case had previous knee surgery in this series; therefore, all sixty-five patients met the inclusion criteria and were enrolled in this study.

\section{Establishment of new classification criteria}

This study focused on the number and the combination of injured structures; both femorotibial joint and PF joint factors, and complications such as fractures and neurovascular injury. Based on the number of injured structures, cases with two injured structures were categorized as Type A, with three structures were categorized as Type B, with four structures were categorized as Type C, and with five structures case were categorized as Type D. Injured structure counting was defined as follows: cruciate ligament group, $A C L$ and/or posterior cruciate ligament $(\mathrm{PCL})$; collateral ligament group, medial collateral ligament (MCL) and/or posterolateral corner (PLC); and PF joint group, one of the MPFL or patellar tendon or quadriceps tendon. PLC contained several structures, certainly include the lateral collateral ligament (LCL), popliteus and popliteo-fibular ligament and so on. The primary restrain structure for varus force is $L C L$, and for posterolateral rotatory instability is femoropopliteal complex. Sometimes not only LCL, but also popliteo-fibular ligament is injured together. In the present study, LCL and popliteo-fibular ligament were defined as one category. The PF joint group mainly contained three different structures. However, these structures work together as the knee extensor mechanism with a central focus on the patella. Therefore, these PF joint factors were defined as the same group, and it was rare that two or more structures failed at the same time in this group. Thus, when one of these structures was ruptured, this was counted as PF joint factor failure in this classification.

Depending on the combination of injured structures, each case was subdivided into 1 to 5 in Types $A$ and $B$ and 1 to 3 in Type C. For example, a case with one cruciate ligament and one collateral ligament injury was defined as Type A-1, bi-cruciate ligament injury was defined as Type A-2, both collateral ligament injuries were defined as Type A-3, one cruciate ligament and PF joint factor failure was 
defined as Type A-4, and one collateral ligament and PF joint factor failure was defined as Type A-5. Type D contained five injured structures (bi-cruciate ligaments, both collateral ligaments, and the PF joint factor); therefore, Type D was not subdivided. Additional complications were also subdivided as follows: MLKI with periarticular fracture was defined as $\mathrm{X}$, with neurovascular injury as $\mathrm{Y}$, and both periarticular fracture and neurovascular injury as Z. For example, one cruciate ligament injury and one collateral ligament injury and an additional fracture were classified as Type A-1-X. Details of each category of the new classification are provided in Tables 1, 2 , 3 , and 4 , respectively.

Table 1

New classification Type A: Combination of 2 structures

\begin{tabular}{|c|c|}
\hline Category & Combination of 2 structures \\
\hline Type-A1 & One cruciate ligament + One collateral ligament \\
\hline Type-A2 & Bi-cruciate ligaments \\
\hline Type-A3 & Both collateral ligaments \\
\hline Type-A4 & One cruciate ligament + PF joint factor* \\
\hline Type-A5 & One collateral ligament + PF joint factor \\
\hline Type-A囚-X & with Periarticular fracture \\
\hline Type-A囚-Y & with Neurovascular injury \\
\hline Type-A囚-Z & with Periarticular fracture and Neurovascular injury \\
\hline \multicolumn{2}{|c|}{ : insert category number $1 \sim 5$} \\
\hline \multicolumn{2}{|c|}{ PF joint factor*: include MPFL or patellar tendon or quadriceps tendon rupture } \\
\hline \multicolumn{2}{|c|}{ PF: Patellofemoral } \\
\hline
\end{tabular}

Table 2

New classification Type B: Combination of 3 structures

\begin{tabular}{|ll|}
\hline Category & Combination of $\mathbf{3}$ structures \\
\hline Type-B1 & One collateral ligament + Bi-cruciate ligaments \\
\hline Type-B2 & One cruciate ligament + Both collateral ligaments \\
\hline Type-B3 & One cruciate ligament + One collateral ligament + PF joint factor \\
\hline Type-B4 & Bi-cruciate ligaments + PF joint factor \\
\hline Type-B5 & Both collateral ligaments + PF joint factor \\
\hline Type-B囚-X & with Periarticular fracture \\
\hline Type-B囚-Y & with Neurovascular injury \\
\hline Type-B囚-Z & with Periarticular fracture and Neurovascular injury \\
\hline O: insert category number 1 5 \\
\hline PF joint factor: include MPFL or patellar tendon or quadriceps tendon rupture \\
\hline PF: Patellofemoral
\end{tabular}


Table 3

New classification Type C: Combination of 4 structures

\begin{tabular}{|c|c|}
\hline Category & Combination of 4 structures \\
\hline Type-C1 & Bi-cruciate ligaments + Both collateral ligaments \\
\hline Type-C2 & Bi-cruciate ligaments + One collateral ligament + PF joint factor \\
\hline Type-C3 & Both collateral ligaments + One cruciate ligament + PF joint factor \\
\hline Type-C凶-X & with Periarticular fracture \\
\hline Type-C凶-Y & with Neurovascular injury \\
\hline Type-C凶-Z & with Periarticular fracture and Neurovascular injury \\
\hline \multicolumn{2}{|c|}{ : insert category number 1 3 } \\
\hline \multicolumn{2}{|c|}{ PF joint factor: include MPFL or patellar tendon or quadriceps tendon rupture } \\
\hline PF: Patell & ioral \\
\hline
\end{tabular}

Table 4

New classification Type D: Combination of 5 structures

\begin{tabular}{|ll|}
\hline Category & Combination of $\mathbf{5}$ structures \\
\hline Type-D & Bi-cruciate ligaments + Both collateral ligaments + PF joint factor \\
\hline Type-D-X & with Periarticular fracture \\
\hline Type-D-Y & with Neurovascular injury \\
\hline Type-D-Z & with Periarticular fracture and Neurovascular injury \\
\hline PF joint factor: include MPFL or patellar tendon or quadriceps tendon rupture \\
\hline PF: Patellofemoral & \\
\hline
\end{tabular}

Evaluation for each case

For each case, the final decision regarding the injured structures around the knee joint and complications such as periarticular fracture and neurovascular injury were recorded after careful clinical examination and imaging evaluation including MRI, dynamic X-ray testing, ultrasonography, and CT scan with angiography for detecting vascular injury or minor periarticular fractures, if needed. Periarticular nerve findings were also carefully evaluated. Not only complete paralysis of the lower leg including the foot and toe, but also slight numbness, sensory disturbance, and muscle weakness were evaluated to determine nerve injury. MLKI cases were divided into both KD classification and the present classification.

\section{Results}

Of the total of sixty-five cases, the causes of MLKI were as follows: sixteen traffic accidents, seven fall accidents, four work-related accidents, four involved slipping and twisting, and thirty-four sports accidents. The sports were: volleyball in six cases; judo and soccer in five cases each; baseball, basketball, and rugby football in three cases each; gymnastics and martial arts in two cases each; and wrestling, skiing, badminton, surfing, American football in one case each. Of these sixty-five cases, fifty-one were divided by KD classification as follows: cases of ACL+MCL, ACL+PLC, PCL+PLC, PCL+MCL for a total of thirty-seven as KD-l; four cases of $A C L+P C L$

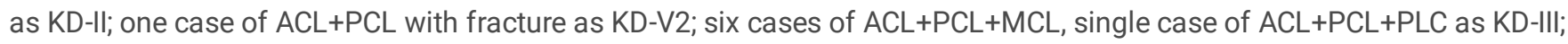
$\mathrm{ACL}+\mathrm{PCL}+\mathrm{PLC}$ with periarticular fracture as $\mathrm{KD}-\mathrm{V} 4$; and $\mathrm{ACL}+\mathrm{PCL}+\mathrm{MCL}+\mathrm{PLC}$ with periarticular fracture as $\mathrm{KD}-\mathrm{V} 5$. Fourteen cases (21.5\%) could not be classified by KD classification. These fourteen cases were follows: two cases of PLC+MPFL and ACL+PLC with periarticular fracture; and single cases of $A C L+M C L+P L C, A C L+P C L+M C L+P L C+M P F L, A C L+M P F L, A C L+M C L+M P F L, P C L+P L C+$ patellar tendon, and $\mathrm{PCL}+$ patellar tendon, $\mathrm{ACL}+\mathrm{PLC}$ with neurovascular injury, and three cases of $\mathrm{PCL}+\mathrm{PLC}$ with complications (periarticular fracture, neurovascular injury, and both combined). Seven of fourteen cases showed PF joint factor injury, with MPFL rupture due to patellar dislocation and patellar tendon rupture. Using the new classification for MLKI, all sixty-five cases were successfully categorized. These fourteen cases were categorized by the new classification as follows: PLC+MPFL as Type-A5; $A C L+P L C$ with periarticular fracture as Type-A1-X; ACL+PLC with neurovascular injury as Type A1-Y; PCL+PLC with periarticular fracture 
as Type-A1-X; PCL+PLC with neurovascular injury as Type-A1-Y; PCL+PLC with periarticular fracture and neurovascular injury as TypeA1-Z; ACL+MCL+PLC as Type-B2; $A C L+P C L+M C L+P L C+M P F L$ as Type-D; $A C L+M P F L$ as Type-A4; $P C L+P L C+$ patellar tendon rupture with periarticular fracture as Type-B3-X; $A C L+M C L+M P F L$ as Type-B3; and PCL+ patellar tendon as Type-A4 (Table 5). 
Table 5

Combination of injured ligament and classification

\begin{tabular}{|c|c|c|c|c|c|c|c|c|c|c|}
\hline & & Injure & struct & & & & & & & \\
\hline Case & $\begin{array}{l}\text { Cause of } \\
\text { injury }\end{array}$ & $\mathrm{ACL}$ & PCL & MCL & PLC & $\begin{array}{l}\text { PF joint } \\
\text { factor }\end{array}$ & $\begin{array}{l}\text { Periarticular } \\
\text { Fracture }\end{array}$ & $\begin{array}{l}\text { Neurovascular } \\
\text { injury }\end{array}$ & $\begin{array}{l}\text { KD } \\
\text { classification }\end{array}$ & $\begin{array}{l}\text { New } \\
\text { classification }\end{array}$ \\
\hline 1 & baseball & ? & & & प & & & ૧ & unclassifiable & Type A1-Y \\
\hline 2 & fall accident & & ( & & प & & & & $\mathrm{KD}-\llbracket \mathrm{L}$ & Type A1 \\
\hline 3 & skiing & ] & ] & प & & & & & $\mathrm{KD}-\otimes \mathrm{M}$ & Type B1 \\
\hline 4 & judo & & ( & ? & & & & & $\mathrm{KD}-\otimes \mathrm{M}$ & Type A1 \\
\hline 5 & $\begin{array}{l}\text { traffic } \\
\text { accident }\end{array}$ & ( & & प & & & & & $\mathrm{KD}-\otimes \mathrm{M}$ & Type A1 \\
\hline 6 & $\begin{array}{l}\text { traffic } \\
\text { accident }\end{array}$ & 0 & 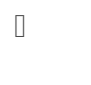 & & & & ( & & KD-V2 & Type A2-X \\
\hline 7 & $\begin{array}{l}\text { traffic } \\
\text { accident }\end{array}$ & $\square$ & 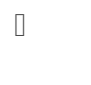 & प & & & & & $\mathrm{KD}-\otimes \mathrm{M}$ & Type B1 \\
\hline 8 & $\begin{array}{l}\text { traffic } \\
\text { accident }\end{array}$ & ? & & & प & & ( & & unclassifiable & Type A1-X \\
\hline 9 & volleyball & ] & प & & & & & & $\mathrm{KD}-\mathbb{\nabla}$ & Type A2 \\
\hline 10 & $\begin{array}{l}\text { traffic } \\
\text { accident }\end{array}$ & ] & & 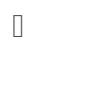 & & & & & $\mathrm{KD}-\otimes \mathrm{M}$ & Type A1 \\
\hline 11 & fall accident & & ] & & $\square$ & & & & $\mathrm{KD}-\bigotimes_{\mathrm{L}}$ & Type A1 \\
\hline 12 & $\begin{array}{l}\text { traffic } \\
\text { accident }\end{array}$ & ] & 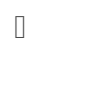 & & & & & & $\mathrm{KD}-\nabla$ & Type A2 \\
\hline 13 & $\begin{array}{l}\text { traffic } \\
\text { accident }\end{array}$ & & ] & & 口 & & & & $\mathrm{KD}-\llbracket \mathrm{L}$ & Type A1 \\
\hline 14 & $\begin{array}{l}\text { labor } \\
\text { accident }\end{array}$ & ( & ] & ( & ] & (MPFL) & & & unclassifiable & Type D \\
\hline 15 & baseball & ] & & ( & & & & & $\mathrm{KD}-\otimes \mathrm{M}$ & Type A1 \\
\hline 16 & fall accident & ( & ] & ( & & & & & $\mathrm{KD}-\otimes \mathrm{M}$ & Type B1 \\
\hline 17 & fall accident & 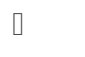 & & & ] & & & & $\mathrm{KD}-\otimes \mathrm{L}$ & Type A1 \\
\hline 18 & judo & ] & & ] & & & & & $\mathrm{KD}-\otimes \mathrm{M}$ & Type A1 \\
\hline 19 & basketball & ( & & & प & & & & $\mathrm{KD}-\llbracket \mathrm{L}$ & Type A1 \\
\hline 20 & fall accident & 0 & & 0 & & & & & $\mathrm{KD}-\otimes \mathrm{M}$ & Type A1 \\
\hline 21 & rugbyfootball & 0 & 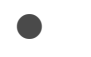 & & & & & & $\mathrm{KD}-\mathbb{\square}$ & Type A2 \\
\hline 22 & $\begin{array}{l}\text { traffic } \\
\text { accident }\end{array}$ & 0 & & & 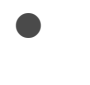 & & & & $\mathrm{KD}-\bigotimes \mathrm{L}$ & Type A1 \\
\hline 23 & martial arts & 0 & & प & & & & & $\mathrm{KD}-\otimes \mathrm{M}$ & Type A1 \\
\hline 24 & $\begin{array}{l}\text { traffic } \\
\text { accident }\end{array}$ & 0 & ○ & & 0 & & & & $\mathrm{KD}-\llbracket \mathrm{L}$ & Type B1 \\
\hline 25 & $\begin{array}{l}\text { traffic } \\
\text { accident }\end{array}$ & 0 & 0 & & 0 & & 0 & & KD-V4 & Type B1-X \\
\hline 26 & soccer & 0 & & 0 & & & & & KD-『M & Type A1 \\
\hline 27 & $\begin{array}{l}\text { traffic } \\
\text { accident }\end{array}$ & 0 & & & 0 & & & & $\mathrm{KD}-\varangle \mathrm{L}$ & Type A1 \\
\hline
\end{tabular}




\begin{tabular}{|c|c|c|c|c|c|c|c|c|c|}
\hline & & Injl & stru & & & & & & \\
\hline 28 & basketball & 0 & & प & & & & $K D-\otimes M$ & Type A1 \\
\hline 29 & $\begin{array}{l}\text { labor } \\
\text { accident }\end{array}$ & 0 & 0 & ૫ & 0 & & - & KD-V5 & Type C1-X \\
\hline 30 & soccer & ( & & 0 & & & & $K D-\varangle M$ & Type A1 \\
\hline 31 & badminton & 0 & & 0 & & & & $\mathrm{KD}-\varangle \mathrm{M}$ & Type A1 \\
\hline 32 & rugbyfootball & & 0 & 0 & & & & $K D-\otimes M$ & Type A1 \\
\hline 33 & $\begin{array}{l}\text { labor } \\
\text { accident }\end{array}$ & $\bullet$ & & प & & & & $K D-\otimes M$ & Type A1 \\
\hline 34 & volleyball & 0 & & प & & & & $K D-\otimes M$ & Type A1 \\
\hline 35 & $\begin{array}{l}\text { traffic } \\
\text { accident }\end{array}$ & & 0 & & $\bullet$ & $\begin{array}{l}\text { (patella } \\
\text { tendon) }\end{array}$ & 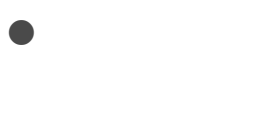 & unclassifiable & Type B3-X \\
\hline 36 & soccer & 0 & & 0 & & & & $K D-\otimes M$ & Type A1 \\
\hline 37 & gymnastic & 0 & 0 & & & & प & KD- $\rrbracket$ & Type A1-Y \\
\hline 38 & volleyball & 0 & & 0 & & & & $K D-\varangle M$ & Type A1 \\
\hline 39 & surfing & 0 & 0 & 0 & & & & $K D-\otimes M$ & Type B1 \\
\hline 40 & $\begin{array}{l}\text { traffic } \\
\text { accident }\end{array}$ & $\bullet$ & 0 & 0 & & & & $K D-\varangle M$ & Type B1 \\
\hline 41 & judo & 0 & & & & $\stackrel{\square}{(\mathrm{MPFL})}$ & & unclassifiable & Type A4 \\
\hline 42 & fall accident & $\bullet$ & & 0 & & (MPFL) & & unclassifiable & Type B3 \\
\hline 43 & $\begin{array}{l}\text { American } \\
\text { football }\end{array}$ & 0 & & ૫ & & & & $K D-\varangle M$ & Type A1 \\
\hline 44 & rugbyfootball & प & ? & प & & & & $K D-\otimes M$ & Type B1 \\
\hline 45 & $\begin{array}{l}\text { traffic } \\
\text { accident }\end{array}$ & & $\bullet$ & & $\bullet$ & & 0 & unclassifiable & Type A1-Z \\
\hline 46 & $\begin{array}{l}\text { slipping and } \\
\text { twisting }\end{array}$ & & & & 0 & (MPFL) & & unclassifiable & Type A5 \\
\hline 47 & basketball & ? & & & प & & & $\mathrm{KD}-\mathbb{-} \mathrm{L}$ & Type A1 \\
\hline 48 & baseball & & & & प & (MPFL) & & unclassifiable & Type A5 \\
\hline 49 & volleyball & - & & ૫ & & & & $K D-\varangle M$ & Type A1 \\
\hline 50 & fall accident & ? & & प & & & & $K D-\otimes M$ & Type A1 \\
\hline 51 & martial arts & ( & & प & प & & & unclassifiable & Type B2 \\
\hline 52 & $\begin{array}{l}\text { slipping and } \\
\text { twisting }\end{array}$ & & ૫ & & & $\begin{array}{l}\text { (patella } \\
\text { tendon) }\end{array}$ & & unclassifiable & Type A4 \\
\hline 53 & $\begin{array}{l}\text { slipping and } \\
\text { twisting }\end{array}$ & & ૫ & & ] & & & $\mathrm{KD}-\mathbb{-} \mathrm{L}$ & Type A1 \\
\hline 54 & gymnastic & प & & & ] & & & 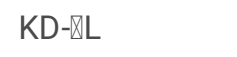 & Type A1 \\
\hline 55 & soccer & ( & & & ( & & & $\mathrm{KD}-\mathbb{-} \mathrm{L}$ & Type A1 \\
\hline 56 & soccer & प & & & प & & & 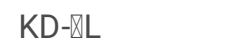 & Type A1 \\
\hline
\end{tabular}




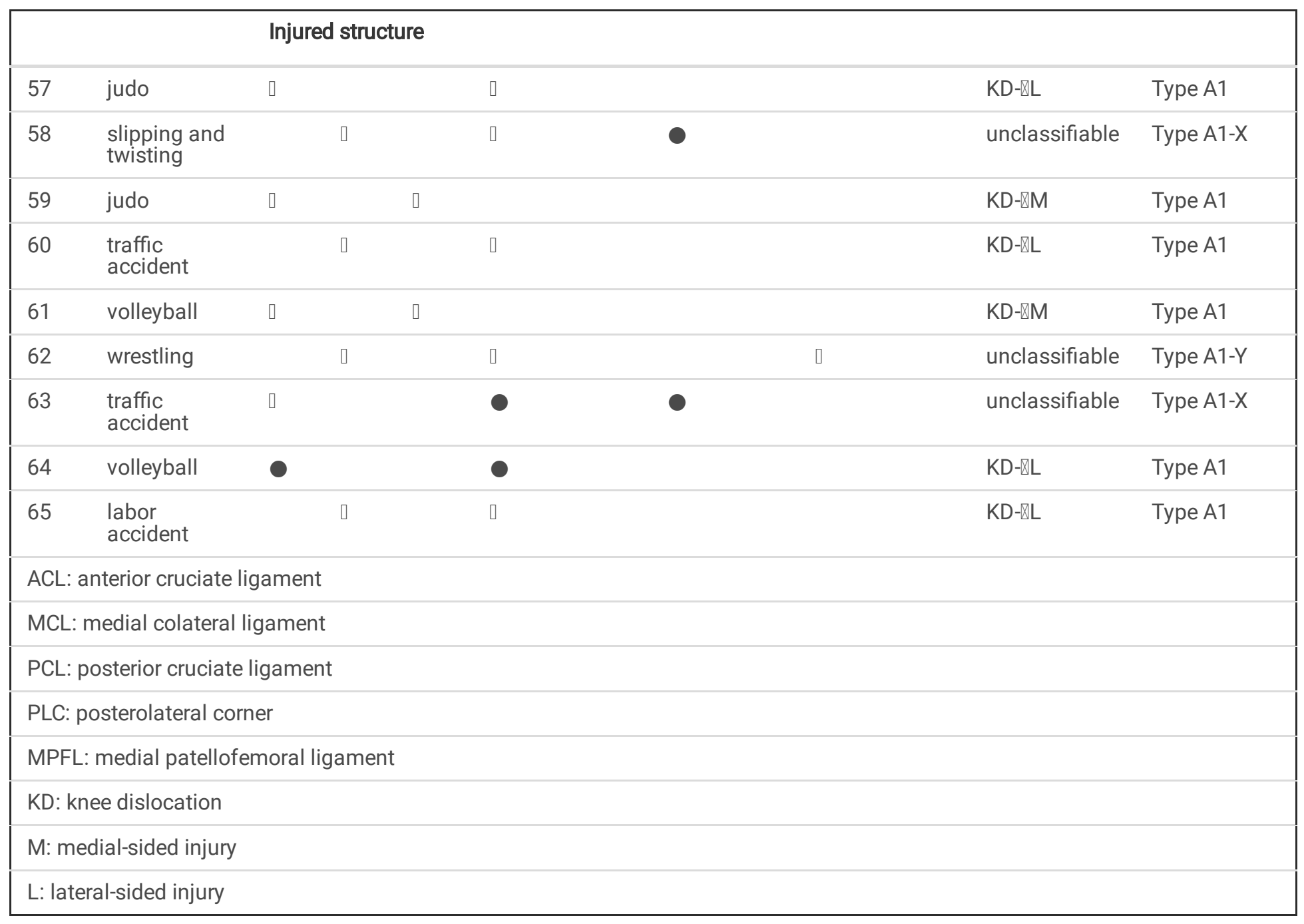

\section{Discussion}

The most important finding of the present study was that all sixty-five MLKI cases were successfully categorized by the new classification without confusion. On the other hand, fourteen cases $(21.5 \%)$ could not be categorized using KD classification. Seven of these fourteen cases contained PF joint factor injuries, with MPFL rupture in five cases and patellar tendon rupture in two cases. MPFL rupture due to patellar dislocation and patellar tendon rupture induce dysfunction and disability of the knee extensor system. Disruption of the knee extensor mechanism are among the targets for treatment, such as reconstruction or repair [10]. For knee surgeons, how many structures are injured, and which structures are injured are key issues for determining the strategy for the graft selection, the surgical procedure, fixation devices, fixation order. Marx et al reported that preoperative planning is critical, and the order of tunnels, graft passage, and fixation should be decided prior to surgery [11].

Knee dislocation or MLKI cases can become very challenging, and even more, sometimes limb-threatening due to neurovascular complications [12-14]. There have been several management protocols and algorithms for treatment of knee dislocation or MLKI cases reported previously $[1,2,12,15]$. Maslaris et al reported a comprehensive initial management protocol for knee dislocation or MLKI that was focused on emergency care taking into account pitfalls and potential complications [16]. Sheth et al suggested that early operative treatment of injured ligaments improved functional and clinical outcomes compared with conservative management or delayed surgery [17]. Fanelli et al concluded that surgical timing for MLKI depends on the ligaments injured, the vascular status of the extremity, reduction stability, and the overall health of the patient [12]. These findings suggest that correct preoperative diagnosis of injured structures and complications, and recognition of the target for treatment are important for surgical planning. However, these previous reports addressed mainly femorotibial joint factors. The combination ruptures of PF joint factors and other ligaments have been reported. De Baere et al presented a case of a combined lesion of the MCL and patellar tendon rupture [18]. In this case, the patellar tendon was reconstructed with a fascia lata allograft, and the MCL was also reconstructed with a semitendinosus tendon autograft. Kim et al reported a case of combined injury of the ACL and patellar tendon; the patellar tendon was repaired with primary 
suture, and the ACL was reconstructed with an Achilles tendon allograft [19]. Levakos et al also reported six cases of combined injuries including ACL and patellar tendon ruptures [20]. In four of six cases, MCL rupture was also present. There is controversy regarding surgical treatment versus nonoperative options for the MPFL after a first-time patellar dislocation [21]. Allen at al reported MPFL injury in MKLI cases. They concluded that an MPFL tear in MLKI rarely caused instability and does not need to be addressed at the time of injury [22]. On the other hand, Gormeli et al presented an MLKI case with ACL, MCL, and MPFL ruptures, and they performed reconstructive surgery for all three injured ligaments with a good clinical outcome [23]. In the present study, six of seven cases with combined PF joint factor injuries underwent surgical treatment due to instability and dysfunction (four for the MPFL and two for the patellar tendon). These findings suggest that PF joint factor injury in MLKI cases may be considered a target of surgical treatment.

Additionally, KD classification, Kennedy's classification, and SOFCOT 2008 classification are based on the presence of dislocation. MLKI without a documented knee dislocation has often been described as a knee dislocation that 'spontaneously reduced' [24]. It is difficult and confusing to apply these previous classifications for the already reduced cases before consultation with the physician in the hospital. MLKI without obvious dislocation or spontaneously reduced cases also provide severe instability and disfunction of the injured knee joint. Therefore, a suitable and systematic classification of MLKI regardless with or without dislocation is needed.

The cause of MLKI injury was categorized for high-energy injury and low-energy injury [25]. Actually, the cause is multifactorial, as follows: direct or indirect force; and magnitude, speed, direction of the external force; rotational or flexion angle of the joints of the hip, knee, and ankle at the time of injury; and so on. Therefore, an inconceivable combination of injured structures can be seen in MLKI cases, sometimes. For example, ACL+MCL+PLC cases are rare in part because the mechanism of injury was difficult to explain. However, a case with this combination of injured ligaments was confirmed in this case series (case 51), and it was also unclassifiable by KD classification. However, we sought to establish a new classification to cover all combination of collateral ligaments, cruciate ligaments, and PF joint factor. Therefore, the rare combinations were remained in the categories.

Complications such as periarticular fracture combined with MLKI were classified as KD-V by Schenck's KD classification [7, 8]. However, the defined categories were sometimes ambiguous, such as KD-V1, which was defined as 'Fracture dislocation without cruciate ligament'. and KD-V2 was defined as 'with isolated bi-cruciate lesion'. KD-V3, -4, and -5 are also based on a bi-cruciate lesion. From this description, it was unclear how many ligaments were ruptured. Eight periarticular fracture cases were seen in the present series. Five of eight cases were unclassifiable by KD classification.; ACL + PLC with periarticular fracture (case 8 and 63), PCL + PLC with fracture (case 45 and 58), PCL +PLC +PF with fracture (case 35). All MLKI with periarticular fracture cases were assigned in the present classification regardless of bi-cruciate ligament injury and of without cruciate ligament injury.

For knee surgeons, comprehensive classification based on the severity and number of targets for surgery has been required. Therefore, we established and proposed a new classification for MLKI that includes every combination all femorotibial and PF joint factors and complications. In the present classification, every combination of MLKI cases with or without complications was successfully classified into a suitable category.

Limitations

Several limitations must be taken into consideration with respect to the present study. First, the study had a small sample size (sixtyfive cases). Second, the MPFL, patellar tendon, and quadriceps tendon were categorized into one group as the 'PF joint factor group' and counted as one. Based on an extensive literature search, there have been no reports of cases that involved both patellar tendon and quadriceps tendon ruptures in the same knee at the same time, as well as no cases of quadriceps tendon rupture and MPFL combined injury. Only one case that involved patellar tendon rupture with injury of the MPFL in a floating knee with proximal tibial and distal femoral fractures has been presented [26]. Rupture of two or more structures of the PF joint factors at the same time seems quite rare in MLKI. Therefore, these structures were classified and counted as one group, such that PF joint factors are considered one knee extensor system in the present classification.

\section{Conclusion}

Disruption of PF joint factors were sometimes combined with other knee ligament ruptures in MLKI cases. Injury of least two structures was confirmed in these cases, and therefore they may be considered as fitting into the MLKI category. However, these combinations were difficult to categorize by any previous classifications for knee dislocation or MLKI. In the present classification, every combination 
of MLKI cases containing both femorotibial and PF joint factors with or without complications was successfully classified into a suitable category.

\section{Abbreviations}

MLKI, multi-ligament knee injury; CT, computed tomography; MRI, magnetic resonance imaging; SOFCOT, The French Society of Orthopedic Surgery and Traumatology; KD, knee dislocation; PF, patellofemoral; ACL, anterior cruciate ligament; MPFL, medial patellofemoral ligament; PCL, posterior cruciate ligament; MCL, medial collateral ligament; PLC, posterolateral corner

\section{Declarations}

Ethics approval and consent to participants.

The experimental design was reviewed and approved (Approval number No. 0-0602) by the Research Ethics Committee of Faculty of Medicine, University of Miyazaki. The procedures followed were in accordance with the ethical standards of the responsible committee on human experimentation (institutional and national) and with the Helsinki Declaration of 1975, as revised in 2013. Information regarding the conduct of this study was disclosed, and research subjects (cases 1-61) were given the opportunity to refuse inclusion in this study. Written, informed consent was obtained from all patients and guardians of prospective research subjects (cases 62-65) for publication of this report and any accompanying images before entering their entry into this study. The patients who did not want to take part were not enrolled in this study.

Author Contribution

Takuya Tajima participated to create the conception, design of the study, performed investigation and acquisition of data.

Yudai Morita, Makoto Nagasawa, Tomomi Ota and Shuichi Kawagoe made substantial contribution to acquisition of data, analyze, interpretation of data.

Takuji Yokoe and Nami Yamaguchi had been involved in drafting the manuscript, and revising it critically for important intellectual content.

Etsuo Chosa participated in the study design and coordination, given final approval of the version to be published. All authors read and approved the final manuscript.

Consent for publication

Not applicable.

Availability of data and materials

All data generated or analyzed during this study are included in this published article and its supplementary information files.

Competing interest

The authors declare that they have no competing interests.

Funding

This study was supported by a Grant for Clinical Research from Miyazaki University Hospital (2020). The funding body had no role in the design of the study, data collection, analysis, interpretation of data and writing the manuscript.

\section{References}

1. Fanelli GC, Stannard JP, Stuart MJ, Macdonald PB, Marx RG, Whelan DB. Management of complex knee ligament injuries. Inst Course Lect. 2011; 60: 523-35. 
2. Peskun CJ, Levy BA, Fanelli GC, Stannard JP, Stuart MJ, MacDonald PB. et al. Diagnosis and management of knee dislocations. Phys Sportsmed. 2010; 38: 101-111. Doi: 10.3810/psm.2010.12.1832.

3. Hiemstra LA, Kerslake S, Heard M, Buchko G, Lafave M. Outcomes of surgical stabilization in patients with combined ACL deficiency and patellofemoral instability - A case series. Knee. 2016; 23: 1106-1111. Doi: 10.1016/j.knee.2016.09.006.

4. Meheux CJ, Jack 2nd RA, McCulloch PC, Lintner DM, Harris JD. Surgical management of simultaneous anterior cruciate ligament and patellar tendon ruptures: A systematic review. J Knee Surg. 2018; 31: 875-883. Doi: 10.1055/s-0037-1615814.

5. Kennedy JC. Complete dislocation of the knee joint. J Bone Joint Surg Am. 1963; 45: 889-904.

6. Boisgard S, Versier G, Descamps S, Lustig S, Trojani C, Rosset P. et al. The French Society of Orthopedic Surgery and Traumatology (SOFCOT). Bicruciate ligament lesions and dislocation of the knee: Mechanism and classification. Orthop Traumatol Surg Res. 2009; 95: 627-631. doi: 10.1016/j.rcot.2009.10.002.

7. Schenck Jr RC. The dislocated knee. Inst Course Lect. 1994; 43: 127-136.

8. Schenck Jr RC, Hunter RE, Ostrum RF, Perry CR. Knee dislocations. Classification of knee dislocations. Inst Course Lect. 1999; 48: 515-522.

9. Maxwell GT, Warth RJ, Amin A, Darlow MA, Bailey L, Lowe WR. et al. Multiple ligament knee injuries: Does the knee dislocation classification predict the type of surgical management? J Knee Surg. 2020; Mar 17. doi: 10.1055/s-0039-1695739.

10. O'Malley M, Reardon P, Pareek A, Krych A, Levy BA, Stuart MJ. Extensor mechanism disruption in knee dislocation. J Knee Surg. 2016; 29: 293-299. doi: 10.1055/s-0035-1568991.

11. Marx RG, Wolfe IA. ACL reconstruction in the multiple ligament injured knee. J Knee Surg. 2020; 33: 418-420. doi: 10.1055/s0039-3400842

12. Fanelli GC. Timing of repair or reconstruction after knee dislocation. J Knee Surg. 2020; 33: 335-338. doi: 10.1055/s-00391700573.

13. Marom N, Ruzbarsky J, Roselaar N, Marx RG. Knee MLI injuries: Common problems and solutions. Clin Sports Med. 2018; 37 : 281-291. doi: 10.1016/j.csm.2017.12.011.

14. Medina O, Arom GA, Yeranosian MG, Pertrigliano FA, McAllister DR. Vascular and nerve injury after knee dislocation. A systematic review. Clin Orthop Relat Res. 2014; 472: 2621-2629. doi: 10.1007/s11999-014-3511-3.

15. Levy BA, Krych AJ, Shah JP, Morgan JA, Stuart MJ. Staged protocol for initial management of the dislocated knee. Knee Surg Sports Traumatol Arthrosc. 2010; 18: 1630-1637. doi: 10.1007/s00167-010-1209-y.

16. Maslaris A, Brinkmann O, Bungartz M, Krettek C, Jagodzinski M, Liodakis E. Management of knee dislocation prior to ligament reconstruction: What is the current evidence? Update of a universal treatment algorithm. Eur J Orthop Surg Traumatol. 2018; 28: 1001-1015. doi: 10.1007/s00590-018-2148-4

17. Sheth U, Sniderman J, Whelan DB. Early stage of multiligament knee injuries may yield better results than delayed surgery: a systematic review. JISAKOS. 2019; 4: 26-32. doi: 10.1136/jisakos-2015-000021.

18. De Baere T, De Muylder J, Deltour A. An unusual knee trauma: Combined rupture of medical collateral ligament and patellar tendon. Case Rep Orthop. 2014; 657296. doi: 10.1155/2014/657296.

19. Kim DH, Lee GC, Park SH. Acute simultaneous ruptures of the anterior cruciate ligament and patellar tendon. Knee Surg Relat Res. 2014; 26: 56-60. doi: 10.5792/ksrr.2014.26.1.56.

20. Levakos Y, Sherman MF, Shelbourne KD, Trakru S, Bonamo JR. Simultaneous rupture of the anterior cruciate ligament and the patellar tendon: Six case Reports. Am J Sports Med. 1996; 24: 498-503. doi: 10.1177/036354659602400415.

21. Erickson BJ, Mascarenhas R, Sayegh ET, Saltzman B, Verma NN, Bush-Joseph CA. et al. Does operative treatment of first-time patellar dislocations lead to increased patellofemoral stability? A systematic review of overlapping meta-analyses. Arthroscopy. 2015; 31: 1207-1215. doi: 10.1016/j.arthro.2014.10.040.

22. Allen BJ, Krych AJ, Engasser W, Levy BA, Stuart MJ, Collins MS. et al. Medical patellofemoral ligament tears in the setting of multiligament knee injuries rarely cause patellar instability. Am J Sports Med. 2015; 43: 1386-1390. doi:

$10.1177 / 0363546515576902$

23. Gormeli G, Gormeli CA, Karakaplan M, Gurbuz S, Ozdemir Z, Ozer M. Acute patellar dislocation with multiple ligament injuries after knee dislocation and single session reconstruction. J Pak Med Assoc. 2016; 66: 757-760.

24. Kahan JB, Schneble CA, Li D, Petit L, Huang P, Bullock J. et al. Increased neurovascular morbidity is seen in documented knee dislocation versus multiligament knee injury. J Bone Joint Surg Am. 2021; 103: 921-930. Doi. 10.2106/JBJS.20.01151.

Page $12 / 13$ 
25. Dean RS, DePhillipo NN, Kahat DH, Graden NR, Larson CM, LaPrade RF. Low-energy multiligament knee injuries are associated with higher postoperative activity scores compared with high-energy multiligament knee injuries: A systematic review and metaanalysis of the literature. Am J Sport Med. 2021; 49: 2248-2254. Doi. 10.1177/0363646520962088.

26. Vaidyanathan S, Ganesan JP, Sengodan MM. Floating knee injury associated with patellar tendon rupture: A case report and review of literature. Case Rep Orthop. 2012: 923230. doi: 10.1155/2012/913230 